\title{
Stable Chronic Obstructive Pulmonary Disease (COPD) Management Under a Tiered Medical System in China
}

\author{
Ruolin Mao $\mathbb{D}^{1, *}$ \\ Zilong Liu'* \\ Yunfeng Zhao ${ }^{2, *}$ \\ Chunlin Du $\mathbb{1 D}^{3, *}$ \\ Jintao Zhou ${ }^{4, *}$ \\ Qian Wang ${ }^{5, *}$ \\ Jinchang $\mathrm{Lu}^{3}$ \\ Lei Gao' \\ Bo Cui' \\ Yuan Ma' \\ Tieying Sun ${ }^{6}$ \\ Lei Zhu ${ }^{1,7}$ \\ Zhihong Chen'
}

'Department of Respiratory and Critical Care Medicine, Zhongshan Hospital, Fudan

University. Shanghai Institute of Respiratory

Disease, Shanghai, People's Republic of China;

${ }^{2}$ Department of Respiratory Disease, Punan

Hospital, Pudong New Area, Shanghai, People's Republic of China; ${ }^{3}$ Department of Respiratory and Critical Care Medicine, Qingpu Branch of

Zhongshan Hospital Affiliated to Fudan

University, Shanghai, People's Republic of

China; ${ }^{4}$ Department of Respiratory and Critical

Care Medicine, Taicang Hospital Affiliated with

Soochow University, Taicang, Jiangsu, People's

Republic of China; ${ }^{5}$ Department of Respiratory Medicine, Jing'an District Zhabei Central

Hospital, Shanghai, People's Republic of China;

${ }^{6}$ Department of Respiratory and Critical Care Medicine, Beijing Hospital, National Center of Gerontology, Beijing, People's Republic of

China; ${ }^{7}$ Department of Respiratory and Critical

Care Medicine, Beijing Tsinghua Changgung

Hospital, Beijing, People's Republic of China

*These authors contributed equally to this work

Correspondence: Zhihong Chen;

Tieying Sun

Tel +86-2I-64041990-2445;

$+86-10-85132266$

Fax +86-2I-64I87|65; +86-10-65I32969

Email chen.zhihong@zs-hospital.sh.cn;

suntieying@|26.com
Background: Early diagnosis and proper management of a large number of chronic obstructive pulmonary disease (COPD) patients are great challenges for the Chinese health care system. Although tiered medical services have been promoted by the Chinese government since 2015, they have not been ideally implemented for COPD diagnosis and management.

Patients and Methods: We designed a cross-sectional study. Eligible COPD patients ( $\mathrm{n}=$ $648)$ and physicians $(\mathrm{n}=161)$ were consecutively recruited from 8 hospitals in different tiers in China. COPD characteristics and treatments were compared among hospitals in different tiers. Multivariate logistic regression was performed to identify risk factors associated with airflow limitation, symptoms and acute exacerbation.

Results: The PFT rate at first diagnosis was $99 \%, 69.4 \%$ and $29.9 \%$ in teaching, second-tier and community hospitals $(\mathrm{P}<0.001)$. Only approximately $10.9 \%, 1.7 \%$ and $9.6 \%$ and $21.8 \%, 6.9 \%$ and $32 \%$ of COPD patients received influenza or pneumococcal vaccines (P $<0.001)$. The proportion of patients who did not use inhaled drugs or had irregular inhalation was $2 \%, 24.6 \%$ and $78.8 \%(\mathrm{P}<0.001)$. Education level $(\mathrm{RR}-1=-41.26 \%, \mathrm{P}=0.007)$, FEV1\%pred (RR-1 $=-2.76 \%, \mathrm{P}<0.001)$, and influenza vaccination in the last year (RR-1 = $-64.53 \%, \mathrm{P}=0.006)$ were all negatively correlated with COPD acute exacerbation (AE). COPD duration $(\mathrm{RR}-1=131.73 \%, \mathrm{P}=0.009), \mathrm{AE}(\mathrm{RR}-1=151.39 \%, \mathrm{P}<0.001)$, and $\mathrm{COPD}$ Assessment Test (CAT) scores (RR-1 $=3.82 \%, \mathrm{P}=0.019)$ were all positively correlated with COPD airflow limitation severity.

Conclusion: Differences exist in the diagnosis, treatment and management of COPD among different tiers of hospitals in China. Teaching hospitals can manage COPD patients relatively well. There are still some gaps compared with developed countries.

Keywords: stable chronic obstructive pulmonary disease, tiered medical system, airflow limitation, symptoms, acute exacerbation

\section{Introduction}

Chronic Obstructive Pulmonary Disease (COPD) is now one of the top three causes of death worldwide and $90 \%$ of these deaths occur in low- and middle-income countries. ${ }^{1}$ A Chinese national cross-sectional survey study reported that the prevalence of spirometry-defined COPD in people aged 40 years or older was $13.7 \%$, indicating a disease burden of approximately 99.9 million in China. ${ }^{2}$ Thus, the early diagnosis and proper management of this very large population are great challenges for the Chinese health care system. Patients swarming to high-tier hospitals in large 
cities consume a large number of high-quality medical resources, which increases medical expenses and inconveniences local residents.

Therefore, in 2015, the Chinese government began to promote "tiered medical services", in which diseases are graded by severity, clinical features, difficulty of treatments and so on. Hospitals in different tiers are required to undertake the treatment of diseases in different grades. The tiered medical system is an important component of China's medical reform, aiming to rationally allocate medical resources. Public hospitals are integral components of China's health care system, and all public hospitals were graded into three tiers according to the scale of the hospitals, scientific research direction, talent and technical strength, medical hardware and equipment, etc. Community hospitals are primary hospitals that directly provide the comprehensive services of medical treatment, prevention, rehabilitation and health care to the community. Second-tier hospitals are regional hospitals that provide health services across several communities and are regional medical technology centers. Teaching hospitals are medical centers that provide comprehensive medical treatment and have teaching and research capabilities. Patients can select hospitals according to their own condition, and referrals can also be made between hospitals of different tiers. In general, higher tier hospitals are associated with more severe disease conditions. However, this concept has not been ideally implemented for COPD diagnosis and management in China.

Accordingly, these characteristics of COPD patients and the diagnosis and treatment preferences of doctors in hospitals in different tiers need to be identified. This study is also designed to explore the gaps between the current management capacity of Chinese doctors and the requirements of international guidelines, and to develop new approaches to improve tiered medical services for Chinese COPD patients.

\section{Materials and Methods Study Design and Subjects}

This was a cross-sectional study. Adult subjects $(\geq 18$ years old) diagnosed with COPD were consecutively recruited from the clinics of 8 hospitals in Shanghai and Suzhou from July 2017 to December 2018. These 8 hospitals included one teaching hospital (Zhongshan Hospital, Fudan University), three second-tier hospitals (Qingpu branch of Zhongshan Hospital, Punan Hospital, Taicang
First Peoples Hospital) and four community hospitals (Nanmatou Community Hospital, Jinze Community Hospital, Zhaoxiang Community Hospital, Waitan Community Hospital).

All the subjects had been diagnosed with COPD before, and the diagnosis was confirmed by clinicians. The patients had symptoms such as dyspnea, chronic cough or sputum production, and/or a history of exposure to risk factors for COPD. A pulmonary function test (PFT) is required to make the diagnosis in this clinical context, and a post bronchodilator forced expiratory volume in one second (FEV1)/forced vital capacity (FVC) less than 0.70 confirms the presence of persistent airflow limitation and indicates the presence of COPD in patients with appropriate symptoms and predisposing risk factors. ${ }^{1}$

All patients were recruited in stable condition, which was defined as no exacerbation or respiratory tract infection for at least one month before enrollment. We excluded subjects who were pregnant or breastfeeding or had chronic unstable diseases of other systems or malignancies.

We also surveyed physicians working in the respiratory department in the 8 hospitals to compare the preferences of doctors in hospitals in different tiers to diagnose and treat COPD.

This study was conducted in accordance with the Declaration of Helsinki. The institutional review board at Zhongshan Hospital, Fudan University reviewed and approved this study (2017BJYYEC-080-02). All included patients and physicians gave written informed consent prior to participation.

\section{Data Collection and Clinical Assessments}

Multidimensional assessments that included demographic characteristics, COPD duration, comorbidities, medication use, other treatment conditions, expenses, etc. were performed in all included patients. COPD control was assessed using the COPD Assessment Test (CAT). The latest PFT results, including FVC\%pred, FEV1\%pred and FEV1/FVC, were also recorded.

The occupational information, diagnosis and treatment preferences of all included doctors were recorded.

\section{Statistical Analyses}

The descriptive analyses of variables are presented as n (\%) for categorical data, and continuous data are presented as the mean with standard deviation. We compared continuous variables using one-way ANOVA as 
appropriate and categorical variables using chi-square tests among the three groups. In addition, post hoc Bonferroni comparisons were performed to explore difference between groups, in which the cut-off significance was set at $\alpha / \mathrm{n}(\alpha=0.05, \mathrm{n}$ is the number of comparisons).

We examined the associations between each variable and the CAT score through the use of univariate regression models. Variables associated with the CAT score in the univariate analysis (at $\mathrm{p}<0.05$ ) were included in multivariable models, and then a multiple regression model was established to investigate factors associated with the CAT score.

We considered FEV1\%pred $<50 \%$ in patients with COPD to indicate severe airflow limitation, FEV1\%pred $\geq 50 \%$ to indicate non-severe airflow limitation, outpatient service $\geq 2$ times or hospitalization $\geq 1$ time in the past year to indicate frequent acute exacerbation (AE), and all other conditions indicated nonfrequent AE. Then, we used multivariate logistic regression analysis to investigate the factors that affect COPD airflow limitation severity and AE. Relative risks (RRs) with 95\% confidence intervals (CIs) were calculated.

Age, sex, body mass index (BMI) and smoking status were included in the regression analysis as potential confounders of the COPD AE condition. However, considering that FEV1\%pred was not affected by age, sex or BMI confounders, smoking status was the only confounder of COPD airflow limitation severity that was included.

Data analyses were done with SPSS 23.0 software. Two-sided $\mathrm{P} \leq 0.05$ was considered statistically significant.

\section{Results}

\section{Demographic and Clinical Characteristics of Stable COPD Patients in 3 Tiers of Hospitals in China}

Among 648 participants included in our study, 101 were from teaching hospitals, 350 were from second-tier hospitals and 197 were from community hospitals. The sociodemographic and clinical characteristics of the patients from teaching to community hospitals are shown in Table 1. Age $(68.92 \pm 7.74$ vs $72.26 \pm 9.03$ vs $72.54 \pm 8.51$ years, $\mathrm{P}=0.002)$ and $\mathrm{BMI}(22.84 \pm 3.16$ vs $22.41 \pm 3.87$ vs $23.37 \pm 3.00, \mathrm{P}=0.009$ ) were significantly different among groups. Compared with the teaching group, a higher proportion of the patients from second-tier and community groups lived in villages and had a lower level of education.
Regarding COPD duration, patients in the second-tier group had the longest duration, and those in the teaching group had the shortest duration $(\mathrm{P}<0.001)$. Comorbidities, such as hypertension $(37.6 \%$ vs $44.0 \%$ vs $68.0 \%$, $\mathrm{P}<0.001)$, coronary atherosclerotic heart disease (5.9\% vs $18.0 \%$ vs $37.1 \%, \mathrm{P}<0.001)$ and asthma $(0.0 \%$ vs $4.9 \%$ vs $10.2 \%, \mathrm{P}=0.001$ ), were common in the community group, but the second-tier group had a much higher proportion of patients with bronchiectasis $(1.0 \%$ vs $8.9 \%$ vs $2.5 \%$, $\mathrm{P}=0.001)$.

When COPD was first diagnosed, the utilization rate of PFT decreased with hospital tier $(99.0 \%$ vs $69.4 \%$ vs $29.9 \%, \mathrm{P}<0.001$, teaching vs second-tiered vs community hospitals) (Figure 1C). The highest proportion of patients who underwent PFT in the last year was observed in the teaching group and was significantly lower in both the second-tier and community groups $(67.3 \%$ vs $24.9 \%$ vs $28.9 \%, \mathrm{P}<0.001)$. Unexpectedly, the proportion of patients with COPD AE in the last year was highest in the second-tier group and the lowest in the teaching group (30.7\% vs $77.1 \% 48.7 \%, \mathrm{P}<0.001)$, and the same was true for CAT scores $(11.31 \pm 6.62$ vs $18.85 \pm 8.66$ vs $15.78 \pm 7.75$, $\mathrm{P}<0.001)$.

\section{Inhaled Bronchodilators are Still a Mainstay for Stable COPD, and Gaps Exist Among the 3 Tiers of Hospitals in China}

The proportion of patients who did not use inhaled drugs ( $1 \%$ vs $6.3 \%$ vs $50.3 \%)$ or who used them irregularly ( $1 \%$ vs $18.3 \%$ vs $28.5 \%$ ) increased with hospital tier (Table 2 ). Among patients in the teaching group, regular LAMA or LABA alone was the most common option (33.7\%), followed by regular ICS+LABA+LAMA (31.7\%) and regular ICS+LABA or ICS+LAMA (21.8\%). However, in the second-tier group, $37.7 \%$ of patients chose ICS $+\mathrm{LABA}+\mathrm{LAMA}$, and the proportions of patients using regular LAMA or LABA and ICS+LABA or ICS +LAMA were all $18.3 \%$. ICS+LABA or ICS+LAMA was the most common choice in the community group (Figure 1B). In the community group, the proportion of patients using regular ICS+LABA or ICS+LAMA (10.7\%) and LAMA or LABA (7.1\%) was slightly higher than that using ICS+LABA+LAMA (4.0\%). Surprisingly, LABA +LAMA both together was the rarest regular medication regimen in all three groups ( $10.9 \%$ vs $1.1 \%$ vs $0.5 \%)$. 
Table I Demographic and Clinical Characteristics of Stable COPD Patients in 3 Tiers of Hospitals

\begin{tabular}{|c|c|c|c|c|c|}
\hline Variables & Teaching Hospital & $\begin{array}{c}\text { Second-Tier } \\
\text { Hospital }\end{array}$ & Community Hospital & $\chi^{2} / F$ & $P$ \\
\hline $\mathrm{n}$ & 101 & 350 & 197 & & \\
\hline Male, n(\%) & $83(82.2)$ & $263(75.1)$ & $122(61.9)$ & 16.883 & $<0.001$ \\
\hline Age (year) & $68.92 \pm 7.74$ & $72.26 \pm 9.03$ & $72.54 \pm 8.51$ & 6.410 & 0.002 \\
\hline BMI $\left(\mathrm{kg} / \mathrm{m}^{2}\right)$ & $22.84 \pm 3.16$ & $22.4 I \pm 3.87$ & $23.37 \pm 3.00$ & 4.704 & 0.009 \\
\hline Education, n (\%) & $* 十^{*}$ & & & 109.765 & $<0.001$ \\
\hline Uneducated or primary & $7(6.9)$ & $184(52.6)$ & $109(55.3)$ & & \\
\hline Middle school & $46(45.5)$ & $87(24.9)$ & $53(26.9)$ & & \\
\hline High school & $30(29.7)$ & $66(18.9)$ & $28(14.2)$ & & \\
\hline College or above & $17(16.8)$ & $10(2.9)$ & $\mathrm{I}(0.5)$ & & \\
\hline Unknown & $\mathrm{I}(\mathrm{I} .0)$ & $3(0.9)$ & $6(3.0)$ & & \\
\hline Living condition, n(\%) & $*+*$ & t† & & 68.520 & $<0.001$ \\
\hline City & $89(88.1)$ & $182(52.0)$ & $75(38.1)$ & & \\
\hline Village & $9(8.9)$ & $143(40.6)$ & $106(53.8)$ & & \\
\hline Unknown & $3(3.0)$ & $26(7.4)$ & $16(8.1)$ & & \\
\hline Smoking status, $n(\%)$ & $*_{\dagger}$ & $t+$ & & 29.529 & $<0.001$ \\
\hline Never & $26(25.7)$ & $132(37.7)$ & $99(50.3)$ & & \\
\hline Ever & $68(67.3)$ & $175(50.0)$ & $74(37.6)$ & & \\
\hline Current & $6(5.9)$ & $43(12.3)$ & $22(11.2)$ & & \\
\hline Unknown & $\mathrm{I}(\mathrm{I} .0)$ & $0(0.0)$ & $2(1.0)$ & & \\
\hline Exposure to biomass fuels, $\mathrm{n}(\%)$ & & & & 6.731 & 0.035 \\
\hline Yes & $6(5.9)$ & $18(5.1)$ & $2(1.0)$ & & \\
\hline No & $95(94.1)$ & $332(94.9)$ & $192(97.5)$ & & \\
\hline Unknown & $0(0.0)$ & $0(0.0)$ & $3(1.5)$ & & \\
\hline Influenza vaccination in the last year, $n(\%)$ & & & & 21.601 & $<0.001$ \\
\hline Yes & II (I0.9) & $6(1.7)$ & $19(9.6)$ & & \\
\hline No & $90(89.1)$ & $344(98.3)$ & $174(90.4)$ & & \\
\hline Unknown & $0(0.0)$ & $0(0.0)$ & $4(2.0)$ & & \\
\hline Pneumococcal vaccination in the last 5 years, $n(\%)$ & & & & 58.965 & $<0.001$ \\
\hline Yes & $22(21.8)$ & $24(6.9)$ & $63(32.0)$ & & \\
\hline No & $79(78.2)$ & $326(93.1)$ & $130(66.0)$ & & \\
\hline Unknown & $0(0.0)$ & $0(0.0)$ & $4(2.0)$ & & \\
\hline COPD duration, $n(\%)$ & $*+*$ & tt† & & 82.177 & $<0.001$ \\
\hline$\leq 3$ year & $46(45.5)$ & $46(13.1)$ & $64(32.5)$ & & \\
\hline $3-5$ year & $30(29.7)$ & $73(20.9)$ & $35(17.8)$ & & \\
\hline $5-10$ year & $20(19.8)$ & $87(24.9)$ & $37(18.8)$ & & \\
\hline$>10$ year & $5(5.0)$ & $142(40.6)$ & $59(29.9)$ & & \\
\hline Unknown & $0(0.0)$ & $2(0.6)$ & $2(1.0)$ & & \\
\hline Number of comorbidities, $n(\%)$ & $t+t$ & tt† & & 40.190 & $<0.001$ \\
\hline 0 & $28(27.7)$ & $99(28.3)$ & $19(9.6)$ & & \\
\hline 1 & $41(40.6)$ & $127(36.3)$ & $76(38.6)$ & & \\
\hline 2 & $24(23.8)$ & $80(22.9)$ & $53(26.9)$ & & \\
\hline 3 & $5(5.0)$ & $36(10.3)$ & $41(20.8)$ & & \\
\hline 4 & $3(3.0)$ & $8(2.3)$ & $8(4.1)$ & & \\
\hline \multicolumn{6}{|l|}{ Comorbidities, n(\%) } \\
\hline Hypertension & $38(37.6)$ & I54 (44.0) & $134(68.0)$ & 36.794 & $<0.001$ \\
\hline CAHD & $6(5.9)$ & $63(18.0)$ & $73(37.1)$ & 44.589 & $<0.001$ \\
\hline Diabetes & $10(9.9)^{*}$ & $52(14.9)$ & $38(19.3)$ & 4.702 & 0.095 \\
\hline Asthma & $0(0.0)$ & $17(4.9)$ & $20(10.2)$ & 13.810 & 0.001 \\
\hline Cardiac insufficiency & $4(4.0)$ & $29(8.3)$ & $17(8.6)$ & 2.391 & 0.303 \\
\hline
\end{tabular}

(Continued) 
Table I (Continued).

\begin{tabular}{|c|c|c|c|c|c|}
\hline Variables & Teaching Hospital & $\begin{array}{c}\text { Second-Tier } \\
\text { Hospital }\end{array}$ & Community Hospital & $\chi^{2} / \mathbf{F}$ & $P$ \\
\hline Bronchiectasis & I (I.0) & 31 (8.9) & $5(2.5)$ & 14.300 & 0.001 \\
\hline DVT & $0(0.0)$ & $\mathrm{I}(0.3)$ & $0(0.0)$ & 0.853 & 0.653 \\
\hline PFT at first diagnosis, $n(\%)$ & $100(99.0)$ & $243(69.4)$ & $59(29.9)$ & 152.870 & $<0.001$ \\
\hline PFT in the last year, $n(\%)$ & & & & 71.714 & $<0.001$ \\
\hline Yes & $68(67.3)$ & $87(24.9)$ & $57(28.9)$ & & \\
\hline No & $32(3 \mid .7)$ & $256(72.6)$ & I 40 (7I.I) & & \\
\hline Unknown & I (I.0) & $9(2.6)$ & $0(0.0)$ & & \\
\hline Latest FEVI\%pred & & & & 112.957 & $<0.001$ \\
\hline (GOLD grade), n(\%) & & & & & \\
\hline $\begin{array}{l}\geq 80 \\
(\text { GOLD I) }\end{array}$ & $6(5.9)$ & $2(0.6)$ & $9(4.6)$ & & \\
\hline $\begin{array}{l}50 \sim 79 \\
\text { (GOLD 2) }\end{array}$ & $38(37.6)$ & $38(10.9)$ & $33(16.8)$ & & \\
\hline $\begin{array}{l}30 \sim 49 \\
\text { (GOLD 3) }\end{array}$ & $29(28.7)$ & $34(9.7)$ & $21(10.7)$ & & \\
\hline $\begin{array}{l}<30 \\
(G O L D 4)\end{array}$ & $9(8.9)$ & $24(6.9)$ & $4(2.0)$ & & \\
\hline Unknown & $19(18.8)$ & $252(72.0)$ & $130(66.0)$ & & \\
\hline$A E$ in the last year, $n(\%)$ & $31(30.7)$ & $270(77.1)$ & $96(48.7)$ & 90.003 & $<0.001$ \\
\hline CAT(scores), n(\%) & $|I .3| \pm 6.62$ & $18.85 \pm 8.66$ & $15.78 \pm 7.75$ & 35.905 & $<0.001$ \\
\hline
\end{tabular}

Notes: $\dagger^{+} P<0.01,{ } \dagger \dagger P<0.001$ vs community group, ${ }^{*}+P<0.01,{ }^{*}+* P<0.001$ vs community and second-tier groups, with the Bonferroni correction. Abbreviations: CAHD, coronary atherosclerotic heart disease; DVT, deep vein thrombosis.

\section{Other Pharmacotherapies and} Nonpharmacotherapies for Stable COPD and Differences Among the 3 Tiers of Hospitals in China

The proportion of patients in the second-tier and community groups using expectorants $(31.7 \%$ vs $46.0 \%$ vs $45.2 \%$, $\mathrm{P}=0.032)$ and theophylline $(4.0 \%$ vs $28.0 \%$ vs $34.0 \%$, $\mathrm{P}<0.001)$ was significantly higher than that in the teaching group (Figure 1A). In the second-tier and community groups, some patients received two or more expectorants. In the three groups, ambroxol was the most commonly used expectorant, and the proportion of patients who used ambroxol in the second-tier and community groups was much greater than that in the teaching group $(37.5 \%$ vs $65.2 \%$ vs $85.4 \%$, $\mathrm{P}<0.001)$. Two other commonly used expectorants were carbocysteine ( $15.6 \%$ vs $26.7 \%$ vs $6.7 \%, \mathrm{P}=0.001)$ and myrtol ( $18.8 \%$ vs $15.5 \%$ vs $5.6 \%, \mathrm{P}=0.045)$.

The second-tier group had the highest proportion $(6.9 \%$ vs $37.1 \%$ vs $8.1 \%, \mathrm{P}<0.001)$ and longest duration of home oxygen therapy in the last year, with similar findings for home noninvasive positive pressure ventilation (HNPPV) (3.0\% vs $10.5 \%$ vs $1.0 \%, \mathrm{P}<0.001)$.
Patients in the teaching and community groups had a much higher proportion of patients who had been vaccinated against influenza ( $10.9 \%$ vs $1.7 \%$ vs $9.6 \%, \mathrm{P}<0.001)$ and pneumococcus $(21.8 \%$ vs $6.9 \%$ vs $32.0 \%, \mathrm{P}<0.001)$.

\section{Risk Factors Associated with $A E$ in Chinese COPD Patients According to Multivariate Logistic Regression}

Factors associated with COPD AE are shown in Table 3. Education level (RR-1 $=-41.26 \%[-60.00 \%,-13.75 \%]$, $\mathrm{P}=0.007)$, FVC $\%$ pred (RR-1 $=-1.56 \%[-2.72 \%,-0.39 \%]$, $\mathrm{P}=0.009), \quad$ FEV1\%pred $\quad(\mathrm{RR}-1=-2.76 \% \quad[-4.10 \%$, $-1.39 \%$ ], $\mathrm{P}<0.001$ ), FEV1/FVC (RR-1 $=-4.29 \%$ [ $-7.65 \%$, $-0.81 \%], \mathrm{P}=0.016)$, and influenza vaccination in the last year (RR-1 $=-64.53 \%[-83.06 \%,-25.72 \%], \mathrm{P}=0.006$ ) were all negatively correlated with COPD AE. The number of comorbidities (RR-1=33.66\% [14.26\%, 56.35\%], $\mathrm{P}<0.001$ ), COPD duration (RR-1=305.39\% [141.03\%, $581.82 \%], \quad \mathrm{P}<0.001), \quad$ hospital tier $\quad(\mathrm{RR}-1=724.53 \%$ [375.14\%,1330.84\%], $\mathrm{P}<0.001)$, home oxygen therapy duration (RR-1=277.57\% [90.14\%, 649.78\%], $\mathrm{P}<0.001$ ), and HNPPV in the last year (RR-1 $=1168.25 \%[62.85 \%$, 
A al

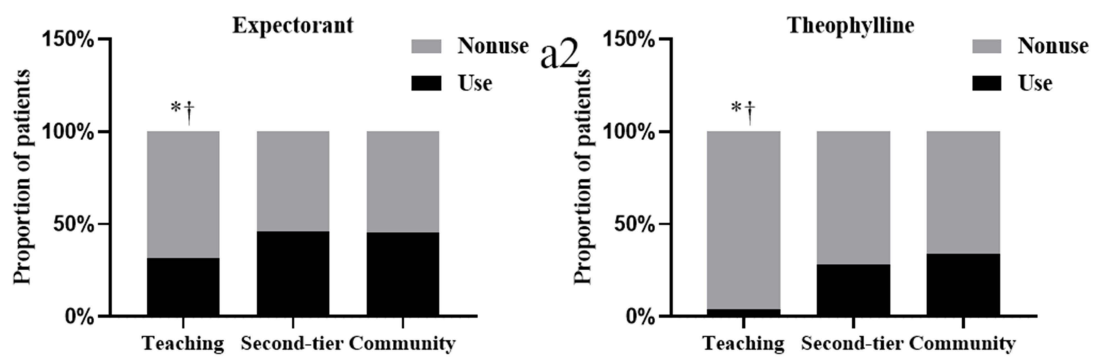

B b
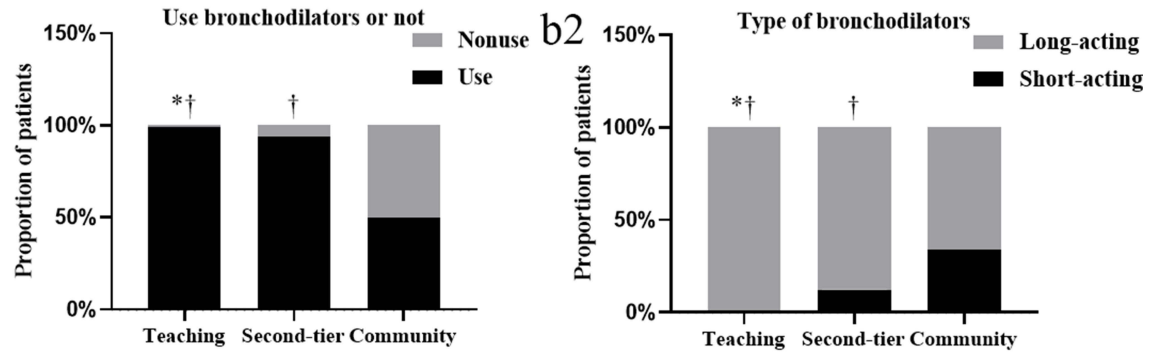

b3
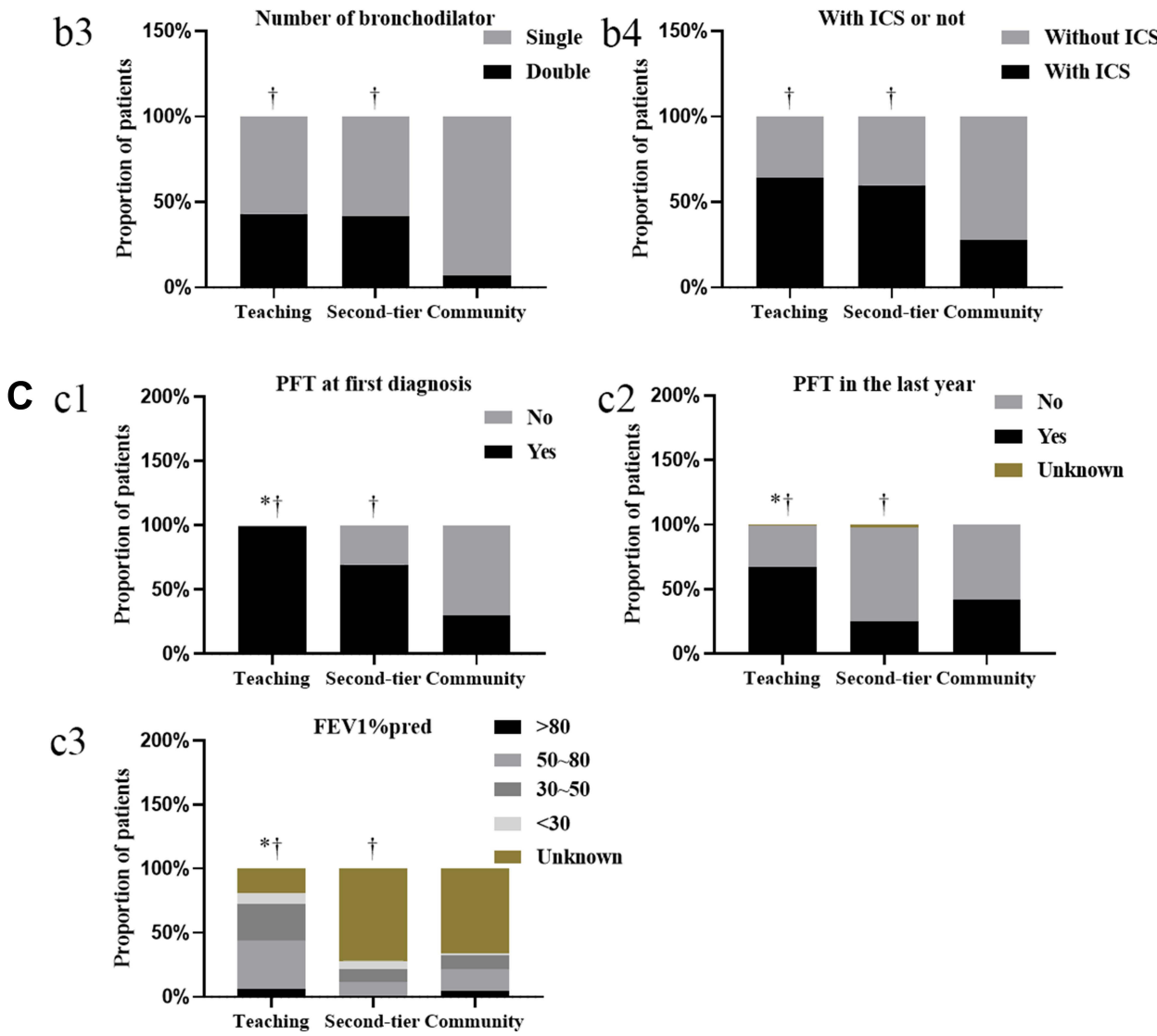

Figure I The usage of bronchodilators, theophylline and expectorants and the PFT situation among stable COPD participants grouped by hospital tier. (A) (al-a2): the usage of theophylline and expectorants. (B) (bl-b4): the usage of bronchodilators. (C) (cl-c3): the PFT situation. $\dagger \mathrm{P}<0.05$ vs community group, $* \mathrm{P}<0.05$ vs second-tier group.

9775.65\%], $\mathrm{P}=0.015$ ) were positively correlated. That is, patients with better lung function, higher levels of education, and influenza vaccination were less likely to have
COPD AE. However, patients with more comorbidities and longer durations of home oxygen therapy and HNPPV were more prone to exacerbation. 
Table 2 The Pharmacotherapies and Nonpharmacotherapies for Stable COPD in 3 Tiers of Hospitals

\begin{tabular}{|c|c|c|c|c|c|}
\hline Variables & $\begin{array}{l}\text { Teaching } \\
\text { Hospital }\end{array}$ & $\begin{array}{c}\text { Second-Tier } \\
\text { Hospital }\end{array}$ & $\begin{array}{c}\text { Community } \\
\text { Hospital }\end{array}$ & $\chi^{2} / F$ & $\mathbf{P}$ \\
\hline $\mathrm{n}$ & 101 & 350 & 197 & & \\
\hline Inhaled drugs, n(\%) & & & & 304.719 & $<0.001$ \\
\hline Regular LAMA or LABA & $34(33.7)$ & $64(18.3)$ & $14(7.1)$ & & \\
\hline Regular LABA+LAMA & $\mathrm{II}(\mathrm{I0.9})$ & $4(1.1)$ & $\mathrm{I}(0.5)$ & & \\
\hline Regular ICS+LABA or ICS+LAMA & $22(21.8)$ & $64(18.3)$ & $21(10.7)$ & & \\
\hline Regular ICS+LABA + LAMA & $32(31.7)$ & $132(37.7)$ & $6(4.0)$ & & \\
\hline Irregular inhaled drugs & $\mathrm{I}(\mathrm{I} .0)$ & $64(18.3)$ & $56(28.5)$ & & \\
\hline No inhaled drugs & $\mathrm{I}(\mathrm{I} .0)$ & $22(6.3)$ & $99(50.3)$ & & \\
\hline Expectorants, $n(\%)$ & $32(31.7)$ & $16 \mid(46.0)$ & $89(45.2)$ & 6.853 & 0.032 \\
\hline \multicolumn{6}{|l|}{ Kind of expectorants, $n(\%)$} \\
\hline Ambroxol & $12(37.5)$ & $105(65.2)$ & $76(85.4)$ & 26.799 & $<0.001$ \\
\hline Carbocysteine & $5(15.6)$ & $43(26.7)$ & $6(6.7)$ & 15.048 & 0.001 \\
\hline Myrtol & $6(18.8)$ & $25(15.5)$ & $5(5.6)$ & 6.215 & 0.045 \\
\hline Others & $9(28.1)$ & $\mathrm{II}(6.8)$ & $7(7.9)$ & 14.418 & 0.001 \\
\hline Theophylline, n(\%) & $4(4.0)$ & $98(28.0)$ & $67(34.0)$ & 32.729 & $<0.001$ \\
\hline Home oxygen therapy in the last year, $n(\%)$ & $7(6.9)$ & $130(37.1)$ & $16(8.1)$ & 77.318 & $<0.001$ \\
\hline $\begin{array}{l}\text { Time of home oxygen therapy in the last year, } \\
n(\%)\end{array}$ & $* * *$ & $t+\dagger$ & & & \\
\hline$\leq 4 \mathrm{~h} /$ day & $2(2.0)$ & $39(11.1)$ & $6(3.0)$ & 79.283 & $<0.001$ \\
\hline $4-8 \mathrm{~h} /$ day & $2(2.0)$ & $45(13.1)$ & $5(2.5)$ & & \\
\hline $8-15 \mathrm{~h} /$ day & $3(3.0)$ & $24(6.9)$ & $4(2.0)$ & & \\
\hline$>15 \mathrm{~h} /$ day & $0(0.0)$ & $21(6.0)$ & $\mathrm{I}(0.5)$ & & \\
\hline None & $94(93.1)$ & $220(62.9)$ & $181(91.9)$ & & \\
\hline HNPPV in the last year, $n(\%)$ & $3(3.0)$ & $37(10.5)$ & $2(1.0)$ & 21.424 & $<0.001$ \\
\hline Time of HNPPV in the last year, $n(\%)$ & & $t+t$ & & 21.524 & $<0.001$ \\
\hline$<4 \mathrm{~h} /$ day & I (I.0) & II (3.I) & I $(0.5)$ & & \\
\hline$>4 \mathrm{~h} /$ day & $2(2.0)$ & $26(7.4)$ & I (0.5) & & \\
\hline None & $98(97.0)$ & $313(89.4)$ & $195(99.0)$ & & \\
\hline
\end{tabular}

Notes: $\dagger+\dagger P<0.001$ vs community group, ${ }^{* * *} P<0.001$ vs second-tier group, with the Bonferroni correction.

\section{Factors Associated with Lung Function Decline in Chinese COPD Patients According to Multivariate Logistic \\ Regression}

Factors associated with COPD airflow limitation severity are shown in Table 4. COPD duration (RR-1=131.73\% [22.88\%, 336.98\%], $\mathrm{P}=0.009)$, home oxygen therapy duration $(\mathrm{RR}-1=325.17 \%[12.97 \%, 1500.15 \%], \mathrm{P}=0.032), \mathrm{AE}$ condition (RR-1=151.39\% [51.54\%, 317.03\%], $\mathrm{P}<0.001$ ), CAT scores $(\mathrm{RR}-1=3.82 \%[0.62 \%, 7.13 \%], \mathrm{P}=0.019)$, and regularity of inhaled drug use (RR-1 $=239.50 \%$ [29.09\%, $729.88 \%$ ], $\mathrm{P}=0.013$ ) were all positively correlated with COPD airflow limitation severity. These results suggest that COPD patients with more severe airflow limitation were more likely to have a longer history of disease. These patients usually had more frequent AEs and higher CAT scores. As a result, they needed longer home oxygen therapy durations to improve symptoms, and they use inhaled drugs more regularly because of the attention and desire to control the disease.

\section{Risk Factors Associated with Symptoms Among Chinese COPD Patients According to Multiple Regression}

Two continuous variables (age and number of symptoms), four binary variables (AE in the last year, PFT in the last year, regularity of inhaled drug use, pneumococcal vaccination in the last 5 years) and one two dummy variables about COPD duration (COPD duration 1: COPD duration $>10$ years, COPD duration 2: 5 years $<$ COPD duration $\leq 10$ years) were incorporated into the model. 
Table 3 Risk Factors Associated with AE in Chinese COPD Patients According to Multivariate Logistic Regression

\begin{tabular}{|c|c|c|c|c|}
\hline Variables & RR-I & Lower $95 \% \mathrm{Cl}$ & Upper $95 \% \mathrm{Cl}$ & $\boldsymbol{P}$ \\
\hline Number of comorbidities & $33.66 \%$ & $14.26 \%$ & $56.35 \%$ & $<0.001$ \\
\hline COPD duration & $305.39 \%$ & $141.03 \%$ & $581.82 \%$ & $<0.001$ \\
\hline Hospital tier & $724.53 \%$ & $375.14 \%$ & $1330.84 \%$ & $<0.001$ \\
\hline Number of symptoms & $103.45 \%$ & $69.11 \%$ & $144.77 \%$ & $<0.001$ \\
\hline Home oxygen therapy time & $277.57 \%$ & $90.14 \%$ & $649.78 \%$ & $<0.001$ \\
\hline HNPPV in the last year & $1168.25 \%$ & $62.85 \%$ & $9776.65 \%$ & 0.015 \\
\hline CAT scores & $14.28 \%$ & $11.44 \%$ & $17.19 \%$ & $<0.001$ \\
\hline Education & $-41.26 \%$ & $-60.00 \%$ & $-13.75 \%$ & 0.007 \\
\hline FVC\%pred & $-1.56 \%$ & $-2.72 \%$ & $-0.39 \%$ & 0.009 \\
\hline FEVI\%pred & $-2.76 \%$ & $-4.10 \%$ & $-1.39 \%$ & $<0.001$ \\
\hline FEVI/ FVC & $-4.29 \%$ & $-7.65 \%$ & $-0.81 \%$ & 0.016 \\
\hline Influenza vaccination in the last year & $-64.53 \%$ & $-83.06 \%$ & $-25.72 \%$ & 0.006 \\
\hline Pneumococcal vaccination in the last 5 years & $-47.92 \%$ & $-66.01 \%$ & $-20.22 \%$ & 0.003 \\
\hline
\end{tabular}

Notes: RR adjusted for age, sex, BMI and smoking status. Number of comorbidities, number of symptoms, CAT scores, FVC\%pred, FEVI\%pred, FEVI/ FVC: continuous variable; education: uneducated or primary $=0$, middle school $=$ I, high school $=2$, college or above $=3$; COPD duration: $\leq 3$ year $=0,3-5$ year $=I, 5-10$ year $=2,>10$ year $=3$; hospital tier: Teaching=I, Second-tier=2, Community 3 ; home oxygen therapy time: none $=0, \leq 4 \mathrm{~h} /$ day $=1,4-8 \mathrm{~h} /$ day $=2,8-15 \mathrm{~h} /$ day $=3,>15 \mathrm{~h} /$ day $=4$; regularity of inhaled drugs: irregular $=0$, regular $=$ I; HNPPV in the last year, influenza vaccination in the last year, pneumococcal vaccination in the last 5 years: no $=0$, yes $=1$.

A formula for CAT score estimation could be obtained: CAT score $\approx 2.074+0.113 \times$ age $+2.744 \times$ number of symptoms $+1.016 \times \mathrm{AE}$ in the last year $+3.176 \times \mathrm{COPD}$ duration $1+3.071 \times \mathrm{COPD}$ duration $2-2.550 \times \mathrm{PFT}$ in the last year - $2.077 \times$ regularity of inhaled drug use $1.645 \times$ pneumococcal vaccination in the last 5 years. The results showed that the CAT scores increased with age, duration of COPD, AE and number of symptoms. Regular PFT, regular inhaled drug use and pneumococcal vaccination could reduce the CAT scores, showing benefits for patients.

\section{Occupational Information and Treatment Preferences of Doctors in the 3 Tiers of Hospitals in China}

The results are shown in Table 5. Among the 161 doctors included in our study, 68 were from teaching hospitals, 50 were from second-tier hospitals and 43 were from community hospitals In addition to respiratory doctors, there were a small number general practitioners and general physicians, almost all of whom work in community hospitals. The community group had the lowest educational level. The proportion of female physicians was the lowest in teaching hospitals and the highest in community hospitals, but there was no statistical significance among the three groups, which were $52.9 \%, 66.0 \%$ and $67.4 \%$ respectively.

The three groups had similar work experience, but there were differences in how to diagnose COPD. In the teaching group, all doctors considered using PFT for diagnosis, and most of these doctors combined chest imaging with PFT. However, in the second-tier and community groups, some doctors considered using only chest imaging to confirm the diagnosis. Even though there was no significant difference, we could see that there were more doctors in the teaching group who recommended PFT for symptomatic patients $(100 \%$ vs $94.0 \%$ vs $90.7 \%$, $\mathrm{P}=0.051)$, followed the guidelines $(97.1 \%$ vs $88.0 \%$ vs

Table 4 Factors Associated with Lung Function Decline in Chinese COPD Patients According to Multivariate Logistic Regression

\begin{tabular}{|l|c|c|c|c|}
\hline Variables & RR-I & Lower 95\% Cl & Upper 95\% Cl & P \\
\hline COPD duration & $131.73 \%$ & $22.88 \%$ & $336.98 \%$ & 0.009 \\
Home oxygen therapy time & $325.17 \%$ & $12.97 \%$ & $1500.15 \%$ & 0.032 \\
AE condition & $151.39 \%$ & $51.54 \%$ & $317.03 \%$ & $<0.001$ \\
CAT scores & $3.82 \%$ & $0.62 \%$ & $7.13 \%$ & 0.019 \\
Regularity of inhaled drugs & $239.50 \%$ & $29.09 \%$ & $792.88 \%$ & 0.013 \\
\hline
\end{tabular}

Notes: RR adjusted for smoking status. CAT scores: continuous variable; COPD duration: $\leq 3$ year $=0,3-5$ year $=1,5-10$ year $=2$, $>10$ year $=3$; home oxygen therapy time: none $=0, \leq 4 \mathrm{~h} /$ day $=1,4-8 \mathrm{~h} /$ day $=2,8-15 \mathrm{~h} /$ day $=3,>15 \mathrm{~h} /$ day $=4 ; A E$ condition: outpatient service $\geq 2$ times or hospitalization $\geq I$ time in the last year $=\mathrm{I}$, outpatient service $\leq \mathrm{I}$ time and no hospitalization in the last year $=0$. Regularity of inhaled drugs: irregular $=0$, regular $=$ I. 
$88.4 \%, \mathrm{P}=0.123)$ and emphasized quitting smoking (100\% vs $94.0 \%$ vs $90.7, \mathrm{P}=0.051)$ and pulmonary rehabilitation $(80.9 \%$ vs $72.0 \%$ vs $74.4 \%, \quad \mathrm{P}=0.500)$. Doctors in the second-tier group were less likely to recommend vaccines to patients than those in the teaching and community groups $(69.1 \%$ vs $48.0 \%$ vs $74.4 \%, \mathrm{P}=0.015)$.

\section{Discussion}

In China, patients in both urban and rural areas can choose any hospital for treatment voluntarily. There is no clear restriction in government policy, and only a slight difference in medical fees. Therefore, most patients are willing to go to a better hospital to receive better medical services, which to some extent leads to the waste of medical resources. Under this background, China began to implement the tiered hospital system nationwide. Teaching hospitals are usually medical centers that are mainly responsible for treating critically ill patients and patients with difficult diseases, teaching medical students and leading the development of new drugs and new treatment. Second-tier hospitals, which are in the middle of the three tiers, are often responsible for local medical services and provide treatment for patients with common and chronic diseases. Community hospitals have insufficient medical resources and focus on health consultation, chronic disease maintenance and prevention. Data reveal that there were approximately 2749 teaching hospitals, 9687 second-tier hospitals and 11,264 community hospitals in 2019 in China. ${ }^{3}$ Ideally, COPD should be first diagnosed and critical, difficult disease should be treated in teaching hospitals. Common and standardized treatments are performed in second-tier hospitals, and disease maintenance, prevention and education are provided in community hospitals. However, the structure of the disease population exhibits a pattern opposite of this pyramid pattern.

In our study, the proportion of patients with COPD AE in the last year was highest in the second-tier group and the lowest in the teaching group, and the same was true for CAT scores. This is not in line with the expectations of tiered hospital system, and there is a gap with developed countries. Combined with the other findings of our study, such as regular medication and PFT complete situation, we infer that this may be related to the limitation of the medical resources and inadequate health education of second-tier hospitals, and the lack of attention or understanding of patients themselves, thus failing to receive fully adequate treatment and rehabilitation guidance. In addition to actual medical resource needs, patients who choose teaching hospitals may also pay more attention to their own health and have better compliance in treatment.

Spirometry is a core part of COPD diagnosis and assessment. Our study showed that the use of PFT is insufficient, especially in second-tier hospitals and community hospitals. The rates of PFT at first diagnosis were 69.4\% and 29.9\%, and PFT follow-up in the previous year was $24.9 \%$ and $28.9 \%$ in these two tiers of hospitals, which are far lower than those in teaching hospitals.

Inadequate PFT availability and people's awareness contribute to the difference between teaching hospitals and the other two tiers of hospitals. PFT in China began in the 1930s, increased in the late 1970s and began to develop rapidly in the late $1990 \mathrm{~s}$, the duration of the

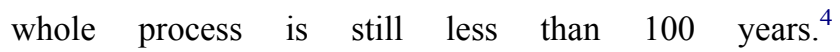
Unsurprisingly, spirometers are far less popular than blood pressure meters and blood glucose meters at present in China. The PFT rate among residents aged 40 years or older in China is very low, ${ }^{5}$ and only $12.0 \%$ of people with COPD reported a previous PFT. ${ }^{1}$ All of the surveyed doctors in the teaching group recommended PFT to symptomatic patients, and the proportion was relatively lower in the other two groups ( $100 \%$ vs $94 \%$ vs $90.7 \%, \mathrm{P}=0.051$ ). It was not until 2015 that China started standardized training and assessment of the clinical application and quality control of PFT nationally. ${ }^{6}$ To date, not only is there a shortage of professional technicians nationwide, but measurement standardization is also not guaranteed. Patients' awareness was also different among the three groups of hospitals. There were more urban residents and patients with higher education in the teaching group, whereas in the other two tiers of hospitals, more patients were from rural areas and had lower education.

In our study, all the second-tier hospitals we included had PFT labs and technicians, but they started relatively late. Therefore, when COPD patients need PFT, they may prefer to go to teaching hospitals with more advanced equipment and experienced technicians and physicians. It is also worth mentioning that even in long-term COPD patients, many patients still do not understand the importance of PFT, and regular follow-up of PFT is difficult to implement. However, doctors in teaching hospitals, especially well-known experts, are more authoritative to patients, and their health education to patients are more significant.

Therefore, to better manage COPD, it is necessary to promote and widely install spirometers to make PFT as convenient as blood pressure/glucose measurement. In 
Table 5 Occupational Information and Medical Preferences of Doctors in 3 Tiers of Hospitals

\begin{tabular}{|c|c|c|c|c|c|}
\hline Variables & $\begin{array}{l}\text { Teaching } \\
\text { Hospital }\end{array}$ & $\begin{array}{c}\text { Second-Tier } \\
\text { Hospital }\end{array}$ & $\begin{array}{c}\text { Community } \\
\text { Hospital }\end{array}$ & $\chi^{2} / \mathbf{F}$ & $\mathbf{P}$ \\
\hline $\mathrm{n}$ & 68 & 50 & 43 & & \\
\hline Male, $n(\%)$ & $32(47.1)$ & $22(44.0)$ & $14(32.6)$ & 2.363 & 0.307 \\
\hline Age (year) & $34.89 \pm 4.30$ & $36.84 \pm 6.31$ & $38.40 \pm 5.59$ & 5.660 & 0.004 \\
\hline Education, n(\%) & $* t^{*}$ & $\dagger$ & & 51.867 & $<0.001$ \\
\hline Junior college & $0(0.0)$ & $5(10.0)$ & $7(16.3)$ & & \\
\hline Bachelor & $25(36.8)$ & $3 I(62.0)$ & $35(8 I .4)$ & & \\
\hline Master & $29(42.6)$ & $13(26.0)$ & $\mathrm{I}(2.3)$ & & \\
\hline Doctor & $14(20.6)$ & $\mathrm{I}(2.0)$ & $0(0.0)$ & & \\
\hline Work Experience, n(\%) & $\dagger$ & & & 10.827 & 0.094 \\
\hline$<3$ years & $7(10.3)$ & $2(4.0)$ & $\mathrm{I}(2.3)$ & & \\
\hline $3-5$ years & $9(13.2)$ & $5(10.0)$ & $5(11.6)$ & & \\
\hline $5-10$ years & $27(39.7)$ & $18(36.0)$ & $9(20.9)$ & & \\
\hline$>10$ years & $25(36.8)$ & $25(50.0)$ & $28(65.1)$ & & \\
\hline Recommend PFT for symptomatic patients, n(\%) & $68(100.0)$ & $47(94.0)$ & $39(90.7)$ & 5.957 & 0.051 \\
\hline Diagnosis COPD, $n(\%)$ & $* t^{*}$ & & & 21.892 & 0.001 \\
\hline No special examination & $0(0.0)$ & $\mathrm{I}(2.0)$ & $0(0.0)$ & & \\
\hline Chest imaging examination & $0(0.0)$ & $9(18.0)$ & $7(16.3)$ & & \\
\hline PFT & II (I6.2) & $\mathrm{I}(2.0)$ & $2(4.7)$ & & \\
\hline Chest imaging examination + PFT & $57(83.8)$ & $39(78.0)$ & $34(79.1)$ & & \\
\hline Follow the guidelines, $n(\%)$ & $66(97.1)$ & $44(88.0)$ & $38(88.4)$ & 4.184 & 0.123 \\
\hline Recommend inhaled drugs, $n(\%)$ & $67(98.5)$ & $50(100.0)$ & $40(93.0)$ & 5.144 & 0.076 \\
\hline Recommend rehabilitation, $\mathrm{n}(\%)$ & $55(80.9)$ & $36(72.0)$ & $32(74.4)$ & 1.388 & 0.500 \\
\hline Asking about smoking history, $\mathrm{n}(\%)$ & $68(100.0)$ & $50(100.0)$ & $42(97.7)$ & 2.761 & 0.251 \\
\hline Emphasize quit smoking, n(\%) & $68(100.0)$ & $47(94.0)$ & $39(90.7)$ & 5.957 & 0.051 \\
\hline Recommend vaccination, $n(\%)$ & $47(69.1)$ & $24(48.0)$ & $32(74.4)$ & 8.351 & 0.015 \\
\hline
\end{tabular}

Notes: $\nmid P<0.05$ vs community group, $*+* P<0.001$ vs community and second-tier groups, with the Bonferroni correction. Abbreviations: OCS, oral corticosteroids.

view of the relatively high difficulty in interpreting and measuring associated with PFT, training for doctors and technicians should be improved. Emphasis should also be placed on popularizing PFT and educating patients on the importance of PFT.

In recent years, portable spirometers have been popularized worldwide, ${ }^{7,8}$ and a clinical study in China involving 980 healthy subjects with COPD showed that one kind of portable spirometer was as accurate as $95.3 \%{ }^{9}$ Compared with traditional spirometers, portable spirometers are cheaper and more convenient. Therefore, portable spirometers are suitable for the routine physical examination and screening of healthy people. Moreover, relying on Internet of Things technology, ${ }^{10}$ some portable spirometers can upload, store and view measurement data in the cloud, which is convenient for doctors to compare and evaluate patient data and adjust treatment plans, which helps narrow the medical gap between different tiers of hospitals.

HNPPV can improve pulmonary function, relax respiratory muscles, ${ }^{11}$ reset the sensitivity of the respiratory center to $\mathrm{CO}_{2},{ }^{12}$ and improve sleep quality in severe COPD patients with stable disease, ${ }^{13}$ which are important components of pulmonary rehabilitation therapy. ${ }^{14}$ In our study, only a small proportion of patients received HNPPV ( $3 \%$ vs $10.5 \%$ vs $1.0 \%$ in teaching hospital vs second-tier hospital vs community hospital group), whereas the proportions of patients with very severe airflow limitation (GOLD 4) were 8.9\%, 6.9\% and $2.0 \%$ in the 3 tiers of hospitals, respectively. A metaanalysis including $21 \mathrm{RCTs}$ and 12 observational studies evaluating 51085 patients showed that home bilevel positive airway pressure and noninvasive home mechanical ventilators were all significantly beneficial to COPD patients with hypercapnia. ${ }^{15,16}$ Murphy's study ${ }^{17}$ showed that among patients with persistent hypercapnia following an AE of COPD, adding home noninvasive ventilation to home oxygen therapy prolonged the time to readmission or death within 12 months. A meta-analysis involving 767 Chinese patients from 14 studies also showed that HNPPV could reduce the mortality of patients with stable and 
severe COPD ( $\mathrm{P}=0.002)$ and improve gas exchange, lung function, and quality of life. ${ }^{18}$

The reasons for the low acceptance and popularity of HNPPV are as follows. First, HNPPV requires specialized equipment and is more expensive. HNPPV equipment is not yet covered by health insurance in China. Second, some patients complained about the uncomfortable feeling of wearing a ventilator and were unable to obtain assistance in time. Therefore, doctors should not only attach importance to drug therapy but also strengthen education and guidance on pulmonary rehabilitation therapy, including HNPPV. Internet of Things technology can also be used in parameter monitoring, technical guidance, data feedback and other aspects in the long-term HNPPV process. In this way, HNPPV can be more beneficial to COPD patients.

Pneumococcal and influenza vaccination could decrease lower respiratory tract infections, which is the most common cause of COPD AE. ${ }^{19}$ In 2016-2017, the median influenza vaccine coverage for individuals with chronic medical conditions in Europe was $44.9 \%$, ranging from $15.7 \%$ to $57.1 \%$ across the 7 reporting member states. ${ }^{20}$ In 2019-2020, coverage of high-risk adults between 18 and 64 years with influenza vaccine was $51.4 \%$ in the US. ${ }^{21}$ Pneumococcal vaccination coverage among adults between 19 and 64 years at increased risk for pneumococcal disease was $24.5 \%$ in 2017 in the US. ${ }^{22}$

Our multivariate regression analysis revealed that both vaccines were beneficial in preventing $\mathrm{AE}$ and improving symptoms. However, the vaccination rates remain low, approximately $10.9 \%, 1.7 \%$ and $9.6 \%$ of COPD patients in the three tiers of hospitals received an influenza vaccine, and $21.8 \%, 6.9 \%$ and. $32 \%$ of COPD patients received a pneumococcal vaccine. According to data from Shanghai, China, in the sample of 2,531,227 individuals aged 15 years or older with hypertension, diabetes and COPD, $22.8 \%$ were vaccinated for pneumonia and $0.4 \%$ for influenza in $2017 .^{23}$ In 2014-2015, the pneumococcal vaccination rate was only $0.8 \%$ in COPD patients aged 40 years or older in China. ${ }^{24}$

In China, adult vaccination is performed only in community hospitals, and doctors have more time to educate patients about the importance and benefits of pneumococcal and influenza vaccination, which partially explains why the vaccination rate in community hospitals is relatively higher than that in teaching and second-tier hospitals. China's low vaccination rate may have something to do with the traditional Chinese concept of "don't go to hospital unless you are sick", and Chinese people do not attach great importance to vaccination, except for the vaccination that must be completed after a baby is born. Chinese government has been campaigning hard in recent years to encourage and fund active vaccination. In the wake of the COVID-19 pandemic, this concept is gradually changing. At present, the rate of SARS-CoV-2 vaccination in Chinese adults is very high, and vaccination has been introduced to children. It is believed that in the postCOVID-19 period, people will pay more attention to vaccines, and the increase in government fiscal investment in vaccine development, delivery and publicity will also allow vaccines to protect more people.

Bronchodilator medication is the cornerstone of stable COPD management based on the drug's pharmacological role of widening the airway and reducing dynamic hyperinflation at rest and during exercise. Our survey showed a large difference in inhaled medication use among the 3 tiers of hospitals. The proportion of patients without or irregular inhaled drug use was $2 \%$ vs $24.6 \%$ vs $78.8 \%$, respectively. Medication unavailability and doctors' lack of awareness of the importance in community hospitals might contribute to the lower coverage of inhaled therapy in COPD patients. Since 2014, GOLD has recommended regular long-acting LABA+LAMA for selective group B, group $\mathrm{C}$ and group D COPD patients. Experiments confirmed that compared with patients treated with ICS + LABA, patients treated with LAMA+LABA have fewer exacerbations, a larger improvement in FEV, a lower risk of pneumonia, and more frequent improvement in quality of life. ${ }^{25,26}$ Our study investigated the Chinese population at the end of 2018 and found gaps between the situation in China and the international guidelines. Only 10.4\%, 1.1\% and $0.5 \%$ of COPD patients received double long-acting bronchodilators in the 3 tiers of hospitals, which is even lower than the rates for single long-acting bronchodilators and double or triple therapies with ICS.

Considering the differences in the pathogenesis of COPD and asthma and steroid-related side effects, GOLD recommends prescribing ICS (including ICS double/triple therapy) only for selected COPD patients, for example, more severe, prone to exacerbation and more symptomatic patients. In recent years, blood eosinophils have been adopted as a biomarker to predict the ICS response in COPD patients. ${ }^{27}$ The IMPACT trial showed that in patients with COPD and a history of exacerbations, triple LAMA+LABA+ICS therapy is more effective than LABA+LAMA in individuals with blood eosinophil 
counts of 310 cells $/ \mu \mathrm{L}$ or more than in individuals with counts less than 90 cells $/ \mu \mathrm{L} .{ }^{28}$ Without considering eosinophil counts, the triple combination of LAMA+LABA $+\mathrm{ICS}$ is as effective as LABA+LAMA in preventing AE in real-world clinical practice ${ }^{29}$ and is associated with an increased cardiovascular risk in patients with COPD. ${ }^{30}$ In our study, the proportions of patients receiving ICS $+\mathrm{LABA}$ or ICS+LABA+LAMA therapy were $53.5 \%$, $56.0 \%$ and $14.7 \%$ in teaching, second-tier and community hospitals, respectively. Most stable COPD patients do not undergo blood eosinophil tests during the initial evaluation and follow-up period, except for those suffering an exacerbation. There are still some deficiencies in keeping up with international treatment guidelines in China, and eosinophils should be given much attention.

Theophylline and expectorants are two major alternative medications for Chinese COPD patients, especially in community hospitals. Inhaled drug unavailability and doctors' knowledge might be partially responsible for this finding. The proportion of patients prescribed theophylline was $4.0 \%, 28.0 \%$ and $34 \%$ in three tiers of hospitals, respectively. Theophylline has uncertain efficacy for symptoms of COPD. Some clinical trial results show that theophylline combined with LABA produces a greater improvement in lung function and symptoms than LABA alone, ${ }^{31}$ and low-dose theophylline increases the efficacy of ICS in COPD patients by reducing the incidence of exacerbations. ${ }^{32}$ However, other data suggest that for people with COPD at high risk of exacerbation, low-dose oral theophylline plus ICS confers no overall clinical, health or economic benefit. ${ }^{33}$ However, GOLD still recommends theophylline or theophylline plus bronchodilators as alternative therapies for some COPD patients. The application of expectorants for COPD is currently recommended by clinical practice and guidelines. In our study, approximately $31.7 \%$ to $46.0 \%$ of Chinese COPD patients were treated with mucoactive agents.

Airflow limitation, symptoms and AE are the foundation of stable COPD management (Figure 2). Our multivariable regression analysis revealed that a reduction in AE frequency helped maintain lung function and improve symptoms. Patients with higher pulmonary function have a lower risk of future exacerbation. Regular follow-up PFT and inhaled medication are two major interventions to improve symptoms and quality of life, which eventually delay lung function decline. Influenza and pneumococcal vaccination are worth popularizing in patients with COPD, and the advantages of these vaccines are clearly shown in COPD management.

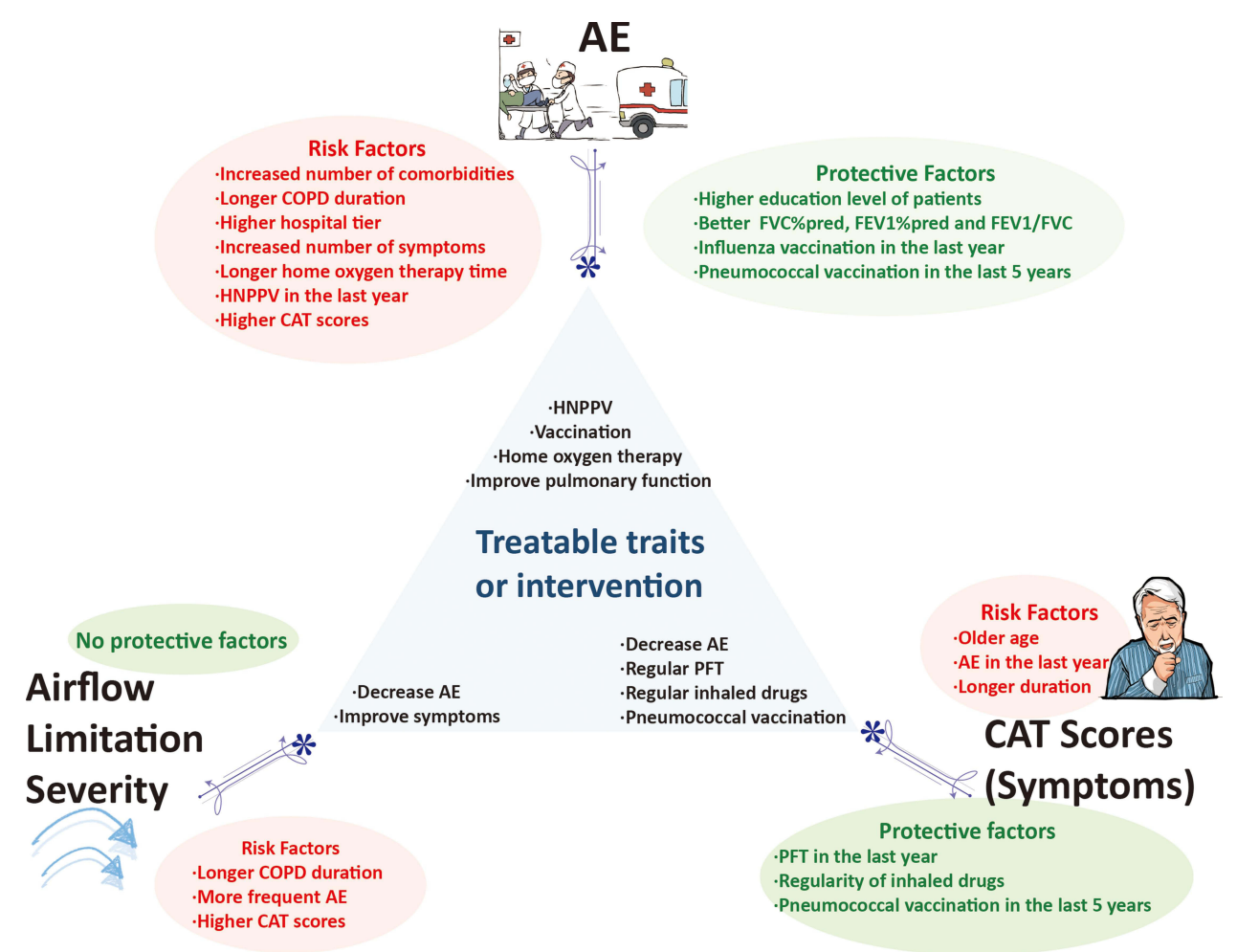

Figure 2 Treatable traits and interventions derived from our multivariate logistic regression analysis to reduce $A E$ and improve lung function and symptoms. 
HNPPV and home oxygen therapy should be recommended to select patients with more serious disease.

\section{Conclusion}

We identified that there are some differences in the diagnosis, treatment and management of COPD among different tiers of hospitals in China, and these differences are related to the level of doctors, patients' socioeconomic conditions, and medical resource allocation among different hospitals. The survey found that teaching hospitals in this region can take charge of the management of COPD patients relatively well, although there are still some gaps compared with COPD management in developed countries. Regular use of inhaled drugs and follow-up of PFT could help reduce AEs and improve airflow limitation and symptoms. Both influenza and pneumococcal vaccinations had a protective effect on COPD patients. However, the rates of PFT and vaccination in China are still not high, so it is necessary to increase financial investment, education and publicity on COPD in China.

\section{Ethics}

This study was conducted in accordance with the Declaration of Helsinki.

\section{Acknowledgments}

This work was supported by National Natural Science Foundation of China (81970023 by ZH Chen), Shanghai Health Committee (201840288 by ZH Chen), National Key Research and Development Program of China, Key Special Projects of Major Chronic Non-Communicable Disease Prevention and Control (2016YFC1304600 by TY Sun), Medical Guidance Project of Shanghai Science and Technology Commission (19411969700 by L Zhu) Shanghai Top-Priority Clinical Key Disciplines Construction Project (2017ZZ02013 by ZH Chen) and Shanghai Municipal Key Clinical Specialty (shslczdzk02201 by $\mathrm{ZH}$ Chen).

\section{Disclosure}

The authors report no conflicts of interest in this work.

\section{References}

1. GOLD. Global strategy for the diagnosis, management and prevention of chronic obstructive lung disease 2021 report [2020-11-01]. Available from: https:/goldcopd.org/wp-content/uploads/2020/11/GOLDREPORT-2021-v1.1-25Nov20_WMV.pdf. Accessed December 31, 2021
2. Wang $\mathrm{C}, \mathrm{Xu} \mathrm{J}$, Yang $\mathrm{L}$, et al. Prevalence and risk factors of chronic obstructive pulmonary disease in China (the China Pulmonary Health [CPH] study): a national cross-sectional study. Lancet. 2018;391(10131):1706-1717. doi:10.1016/S0140-6736(18) 30841-9

3. National Health Commission of the People's Republic of China. Statistical bulletin on the development of China's health undertakings in 2019 [2020-06-06]. Available from: http://www.nhc.gov.cn/gui huaxxs/s10748/202006/ebfe31f24cc145b198dd730603ec4442.shtml. Accessed December 31, 2021.

4. Zheng J. A nationwide questionnaire survey on clinical application of pulmonary function testing in China. Chinese J Tuberculosis Respir Dis. 2002;25:69-73.

5. Fang LW, Bao HL, Wang BH, et al. Survey and analyses of rate of spirometry examination in adults aged 40 years and older in China, 2014. Chinese J Epidemiol. 2018;39:593-599. doi:10.3760/cma.j. issn.0254-6450.2018.05.010

6. Gao Y, Zheng J, Liang J, Wu Q. Overview of standardized training programme for clinical application and quality control of pulmonary function testing in China. Chin $J$ Pract Internal Medic. 2019;39:746-750.

7. Skloot GS, Edwards NT, Enright PL. Four-year calibration stability of the EasyOne portable spirometer. Respir Care. 2010;55:873-877.

8. Bambra G, Jalota L, Kapoor C, et al. Office spirometry correlates with laboratory spirometry in patients with symptomatic asthma and COPD. Clin Respir J. 2017;11:805-811. doi:10.1111/crj.12419

9. Zhou L, Jiang Y, Du C, et al. Development of an internet-of-things based portable spirometer and the validation of its accuracy. Int $J$ Respir. 2019;02:113-118.

10. Gerbase MW, Dupuis-Lozeron E, Schindler C, et al. Agreement between spirometers: a challenge in the follow-up of patients and populations? Respiration. 2013;85(6):505-514. doi:10.1159/ 000346649

11. Gea J, Agusti A, Roca J. Pathophysiology of muscle dysfunction in COPD. J Appl Physiol (1985). 2013;114:1222-1234. doi:10.1152/ japplphysiol.00981.2012

12. Elliott MW, Mulvey DA, Moxham J, Green M, Branthwaite MA. Domiciliary nocturnal nasal intermittent positive pressure ventilation in COPD: mechanisms underlying changes in arterial blood gas tensions. Eur Respir J. 1991;4:1044-1052.

13. Meecham JD, Paul EA, Jones PW, Wedzicha JA. Nasal pressure support ventilation plus oxygen compared with oxygen therapy alone in hypercapnic COPD. Am J Respir Crit Care Med. 1995;152 (2):538-544. doi:10.1164/ajrccm.152.2.7633704

14. Duiverman ML. Noninvasive ventilation in stable hypercapnic COPD: what is the evidence? ERJ Open Research. 2018;4:00012-2018. doi:10.1183/23120541.00012-2018

15. Hoiland RL, Mladinov S, Barak OF, et al. Oxygen therapy improves cerebral oxygen delivery and neurovascular function in hypoxaemic chronic obstructive pulmonary disease patients. Exp Physiol. 2018;103:1170-1177. doi:10.1113/EP086994

16. Wilson ME, Dobler CC, Morrow AS, et al. Association of home noninvasive positive pressure ventilation with clinical outcomes in chronic obstructive pulmonary disease: a systematic review and meta-analysis. JAMA. 2020;323:455-465. doi:10.1001/ jama.2019.22343

17. Murphy PB, Rehal S, Arbane G, et al. Effect of home noninvasive ventilation with oxygen therapy vs oxygen therapy alone on hospital readmission or death after an acute COPD exacerbation: a randomized clinical trial. JAMA. 2017;317:2177-2186. doi:10.1001/jama.2017.4451

18. Liu Y, Fu Q, Dai B, Zhang J. Efficacy of home noninvasive positive pressure ventilation on patients with severe stable chronic obstructive pulmonary disease in China: a meta-analysis. Chin J Respir Crit Care Med. 2019;18:209-216. 
19. Woodhead M, Blasi F, Ewig S, et al. Guidelines for the management of adult lower respiratory tract infections. Eur Respir J. 2005;26:1138-1180. doi:10.1183/09031936.05.00055705

20. ECDC. Seasonal influenza vaccination and antiviral use in EU/EEA Member States [2018-12-18]. Available from: https://www.ecdc. europa.eu/en/publications-data/seasonal-influenza-vaccinationantiviral-use-eu-eea-member-states. Accessed December 31, 2021.

21. CDC. Flu vaccination coverage, United States, 2019-20 influenza season [2020-10-01]. Available from: https:/www.cdc.gov/flu/fluvax view/coverage-1920estimates.htm. Accessed December 31, 2021.

22. CDC. Vaccination coverage among adults in the United States, national health interview survey, 2017 [2018-02-08]. Available from: https://www.cdc.gov/vaccines/imz-managers/coverage/adult vaxview/pubs-resources/NHIS-2017.html. Accessed December 31, 2021.

23. Wang Y, Cheng M, Wang S, et al. Vaccination coverage with the pneumococcal and influenza vaccine among persons with chronic diseases in Shanghai, China, 2017. BMC Public Health. 2020;20:359. doi:10.1186/s12889-020-8388-3

24. Fan J, Cong S, Wang N, et al. Pneumococcal vaccination rate in chronic obstructive pulmonary disease patients aged 40 years or older in China, 2014-2015. Chinese J Epidemiol. 2020;41:1028-1033. doi:10.3760/cma.j.cn112338-20200124-00056

25. Petite SE. Role of long-acting muscarinic antagonist/long-acting $\beta$ 2-agonist therapy in chronic obstructive pulmonary disease. Ann Pharmacother. 2017;51(8):696-705. doi:10.1177/1060028017705149

26. Horita N, Goto A, Shibata Y, et al. Long-acting muscarinic antagonist (LAMA) plus long-acting beta-agonist (LABA) versus LABA plus inhaled corticosteroid (ICS) for stable chronic obstructive pulmonary disease (COPD). Cochrane Database Syst Rev. 2017;2(3):CD012066. doi:10.1152/ajplegacy.1975.229.3.754
27. Roche N, Chapman KR, Vogelmeier CF, et al. Blood eosinophils and response to maintenance chronic obstructive pulmonary disease treatment. Data from the FLAME Trial Am J Respir Crit Care Med. 2017;195:1189-1197. doi:10.1164/rccm.201701-0193OC

28. Pascoe S, Barnes N, Brusselle G, et al. Blood eosinophils and treatment response with triple and dual combination therapy in chronic obstructive pulmonary disease: analysis of the IMPACT trial. Lancet Respir Med. 2019;7:745-756. doi:10.1016/S2213-2600(19)30190-0

29. Suissa S, Dell'Aniello S, Ernst P. Comparative effects of LAMA-LABA-ICS vs LAMA-LABA for COPD: cohort study in real-World Clinical Practice. Chest. 2020;157:846-855. doi:10.1016/j.chest.2019.11.007

30. Liou JT, Lin CW, Tsai CL, et al. Risk of severe cardiovascular events from add-on Tiotropium in chronic obstructive pulmonary disease. Mayo Clin Proc. 2018;93:1462-1473. doi:10.1016/j.mayocp.2018. 05.030

31. Zacarias EC, Castro AA, Cendon S. Effect of theophylline associated with short-acting or long-acting inhaled beta2-agonists in patients with stable chronic obstructive pulmonary disease: a systematic review. J Bras Pneumol. 2007;33:152-160. doi:10.1590/S180637132007000200009

32. Devereux G, Cotton S, Barnes P, et al. Use of low-dose oral theophylline as an adjunct to inhaled corticosteroids in preventing exacerbations of chronic obstructive pulmonary disease: study protocol for a randomised controlled trial. Trials. 2015;16:267. doi:10.1186/ s13063-015-0782-2

33. Devereux G, Cotton S, Fielding S, et al. Low-dose oral theophylline combined with inhaled corticosteroids for people with chronic obstructive pulmonary disease and high risk of exacerbations: a RCT. Health Technol Assess. 2019;23:1-146. doi:10.3310/hta23370

\section{Publish your work in this journal}

The International Journal of COPD is an international, peer-reviewed journal of therapeutics and pharmacology focusing on concise rapid reporting of clinical studies and reviews in COPD. Special focus is given to the pathophysiological processes underlying the disease, intervention programs, patient focused education, and self management protocols. This journal is indexed on PubMed Central, MedLine and CAS. The manuscript management system is completely online and includes a very quick and fair peer-review system, which is all easy to use. Visit http://www.dovepress.com/testimonials.php to read real quotes from published authors. 